\title{
Improved Dynamics of Thoracic Cage and Exercise Capacity after Nuss Repair for Pectus Excavatum
}

\author{
Shu-Wei Yeh ${ }^{1}$ Mei-Chen Yang ${ }^{2,3}$ Yi-Wei Chang ${ }^{2,4}$ \\ Yeung-Leung Cheng ${ }^{1,2}$ \\ ${ }^{1}$ Division of Thoracic Surgery, Department of Surgery, Taipei Tzu Chi \\ Hospital, Buddhist Tzu Chi Medical Foundation, New Taipei City, Taiwan \\ ${ }^{2}$ School of Medicine, Tzu Chi University, Hualien, Taiwan \\ ${ }^{3}$ Division of Pulmonary Medicine, Department of Internal Medicine, \\ Taipei Tzu Chi Hospital, Buddhist Tzu Chi Medical Foundation, New \\ Taipei City, Taiwan \\ ${ }^{4}$ Department of Physical Medicine and Rehabilitation, Taipei Tzu Chi \\ Hospital, Buddhist Tzu Chi Medical Foundation, New Taipei City, Taiwan \\ ${ }^{5}$ Department of Research, Taipei Tzu Chi Hospital, Buddhist Tzu Chi \\ Medical Foundation, New Taipei City, Taiwan \\ Thorac Cardiovasc Surg 2020;68:85-91.
}

\begin{abstract}
Address for correspondence Yeung-Leung Cheng, MD, PhD, Division of Thoracic Surgery, Department of Surgery, Taipei Tzu Chi Hospital, Buddhist Tzu Chi Medical Foundation, No 289, Jianguo RD, Xindian District, New Taipei City, Taiwan 231

(e-mail: ndmc0928@yahoo.com.tw).
\end{abstract}

Yu-Ting Hsu ${ }^{4} \quad$ I-Shiang Tzeng ${ }^{5}$

\begin{abstract}
Keywords

- pectus excavatum

- Nuss procedure

- thoracic cage

- cirtometry

- 6-minute walk test

Background Pectus excavatum (PE) reduces the dynamics of the thoracic cage, with a negative impact on exercise capacity. We aimed to evaluate the effects of Nuss repair for PE on the dynamics of the thoracic cage and exercise capacity in adults.

Methods This was a prospective observational study of 46 adults (mean age, 26.2 years) who underwent PE correction using the Nuss procedure between September 2016 and August 2017. Cirtometry was used to obtain measures of thoracic cage circumference at two levels (axillary level $[\mathrm{AL}]$ and xyphoid level $[\mathrm{XL}]$ ), at the end points of inspiration and expiration. Circumference measures were obtained before surgery and at 1,3, and 6 months after surgery. Exercise capacity was also evaluated using the 6 -minute walk test (6MWT). The association between the 6MWT data and cirtometry measures was evaluated using Pearson's correlation.

Results The circumference at maximum inspiration increased from baseline to 3 months after surgery $(p<0.01)$, at both the $\mathrm{AL}(84.5 \pm 4.9 \mathrm{vs.} 88.5 \pm 5.1 \mathrm{~cm})$ and $\mathrm{XL}(80.1 \pm 4.8$ vs. $83.7 \pm 5.1 \mathrm{~cm})$. The $6 \mathrm{MWT}$ also significantly improved from baseline to 3 months after surgical correction ( $544.7 \pm 64.1$ vs. $637.3 \pm 59.4 \mathrm{~m}, p<0.01)$, with this improvement being correlated to the increase in thoracic circumference on maximal inspiration at both the AL and XL (0.8424 and 0.7951, respectively).

Conclusion Improved dynamics of the thoracic cage were achieved after Nuss repair for $P E$ in adults. This increase in thoracic circumference at maximum inspiration was associated with an improvement in exercise capacity at 3 months after surgery.
\end{abstract}

\section{Introduction}

Pectus excavatum (PE), also known as funnel chest, is the most common congenital deformity of the anterior thoracic wall, and is caused by the overgrowth of the costal cartilage. $\mathrm{PE}$ is predominantly observed at birth but might also become apparent at puberty. ${ }^{1}$ As the child reaches puberty, symptoms of cardiopulmonary compression may be present, including palpitation, chest discomfort, and exercise intolerance. Thus, recently, PE has been considered not only as a cosmetic issue but also as a physiological concern, especially received

October 26, 2018

accepted after revision

January 28, 2019

published online

March 12, 2019 (c) 2020 Georg Thieme Verlag KG Stuttgart · New York
DOI https://doi.org/ 10.1055/s-0039-1683384. ISSN 0171-6425. 
in adult patients. ${ }^{2-4}$ In 1998, Nuss et al documented a minimally invasive surgery for the correction of PE, with good clinical results. This procedure involves placing one or more prebent stainless steel bars underneath the concave part of the chest wall, without resection of the cartilage, so as to push the anterior chest wall outward and, thus, remodel the deformity. ${ }^{5}$

The effects of the Nuss correction on cardiopulmonary function have been discussed in previous studies. ${ }^{6-9}$ However, the effects of the procedure on the dynamics of the thoracic cage, which is associated with exercise capacity, are unclear. Thoracic cirtometry, also known as thoracoabdominal perimeter measurement, is a relatively simple and inexpensive method to provide reliable and repeatable measures of the range of movement of the chest wall from endpoint inspiration to end-point expiration. ${ }^{10,11}$ Additionally, the 6-minute walk test (6MWT), a practical physiological test, provides an assessment of cardiopulmonary function after thoracic surgery that is reproducible, standardized, and reliable. $^{12,13}$ Our aim in this study was to use cirtometry to quantify the changes in the dynamics of the thoracic cage after Nuss correction for PE and to evaluate the association between changes in thoracic cage dynamics and exercise capacity, measured using the 6MWT.

\section{Materials and Methods}

\section{Participants}

A prospective observational study was conducted, comprising adult patients diagnosed with PE who were scheduled for a Nuss procedure for the correction of PE at the Taipei Chi-Tzu Hospital in New Taipei city, Taiwan, between September 2016 and August 2017. Preoperative assessments included a complete history, physical examination, chest radiography, electrocardiography, pulmonary function test, echocardiography, and computed tomography (CT) of the chest. Age, height, body weight, body mass index (BMI), the Haller index (ratio of the transverse thoracic dimension to the sternovertebral dimension at the most depressed point detected on CT of the chest as previously described ${ }^{14}$ ), sternovertebral distance (SVD) on lateral chest radiographs, ${ }^{15}$ and postoperative data were recorded.

Indications for surgical repair followed the criteria described by Nuss and Kelly. ${ }^{2}$ The surgical technique, a bilateral thoracoscopy-assisted Nuss procedure, was performed as previously described. ${ }^{16}$ All patients underwent portable chest radiography and were intensively monitored for 24 hours postoperatively. Postoperative pain was controlled using fentanyl, administered via patient-controlled epidural analgesia. Nonsteroidal antiinflammatory drugs were also provided for pain relief. Patients were discharged from the hospital once the pain was controlled using only oral analgesics. All patients were followed up at 1,3 , and 6 months after surgery and annually thereafter. All patients were discouraged from performing deep breathing exercise after the surgery and resumed normal exercise 3 months after surgery.

This study was approved by our ethics committee and Institutional Review Board (IRB: TTCH-IRB no.: 05-X17-070), and all patients provided informed consent. Patients were excluded from the analysis if they had major complications (e.g., hemothorax, pleural effusion, or bar flipping requiring surgical revision) or were lost to follow-up.

\section{Cirtometry and Exercise Capacity}

Detailed instructions regarding the outcome measures were provided to each participant, including a demonstration prior to measurement.

Different cirtometry methods have been described in the literature; in this study, we used the standardized protocol reported by Caldeira et al. ${ }^{11}$ Measurements were performed by an experienced senior physician (Y.L.C.). All baseline measurements were obtained with the patient standing upright, with arms extended alongside the trunk and the chest uncovered. Using a conventional measuring tape $(\mathrm{cm})$, the circumference of the chest wall was measured at the axillary level (AL) and xiphoid level $(\mathrm{XL})$, using the axillary fold and xyphoid process as anatomical landmarks, respectively ( $\mathbf{F i g}$. 1A, B). During the measurement, considerable care was taken to pull the tape snuggly, but not too tightly, so as to not alter the soft tissue contours. Three measurements were obtained at each level for both inspiration and expiration. At each level, the measurements were performed on maximal inspiration and maximal expiration during separate breaths, with a 1-minute interval between each measurement. Patients were asked to maintain maximal inspiration/expiration status for more than 2 seconds to allow the measurements to be completed. The mean values of the three measurements were recorded by a third observer to ensure blinding. The assessor was also blinded when analyzing the results. All patients were evaluated at four specific time points: preoperatively and at 1, 3, and 6 months after surgery.

The 6MWT was used to evaluate functional exercise capacity before and after surgical correction. The 6MWT was performed as per the guidelines of the American Thoracic Society. ${ }^{13}$ The BMI was obtained at the time of the $6 \mathrm{MWT}$, and pain score was measured using a $10-\mathrm{cm}$ visual analog scale (VAS) measured at the end of the 6MWT. Finally, the correlation between the 6MWT data (time, BMI, and VAS) and cirtometry was analyzed.

\section{Statistical Analysis}

For continuous variables, descriptive data are expressed as means \pm standard deviation (SD) and the Student's $t$-test used to compare postoperative and preoperative values. For categorical variables, the chi-square or Fisher's exact test was used to compare postoperative and preoperative values, as appropriate for the data type. Pearson's correlation coefficient was calculated to evaluate the relationship between cirtometry and 6MWT data (time, BMI, and VAS). A p-value of less than 0.01 was considered significant. Statistical analyses were performed using SPSS software (version 24; SPSS; Chicago, Illinois, United States).

\section{Results}

\section{Clinical Characteristics and Surgical Outcomes}

Initially, 55 patients were enrolled into the study, with 9 patients excluded from the analysis due to pleural effusion 


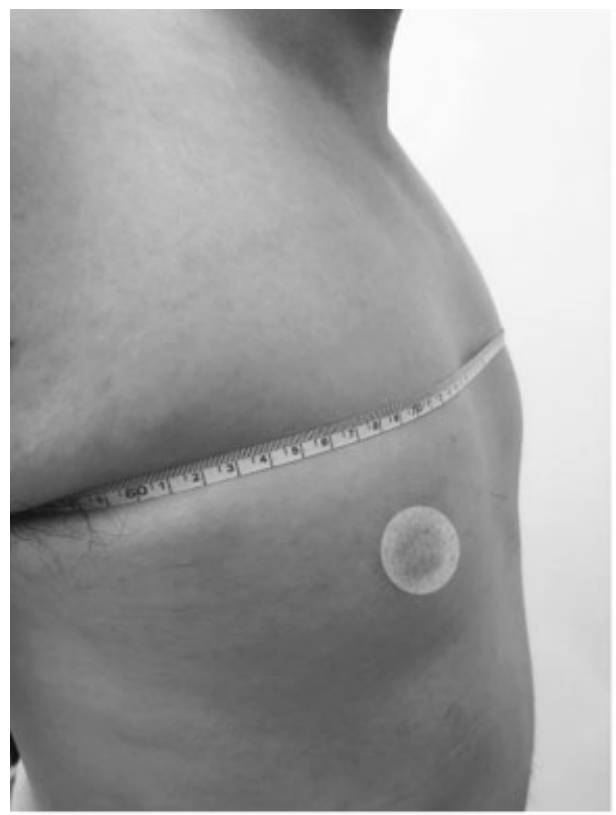

A: on axillary level (AL)

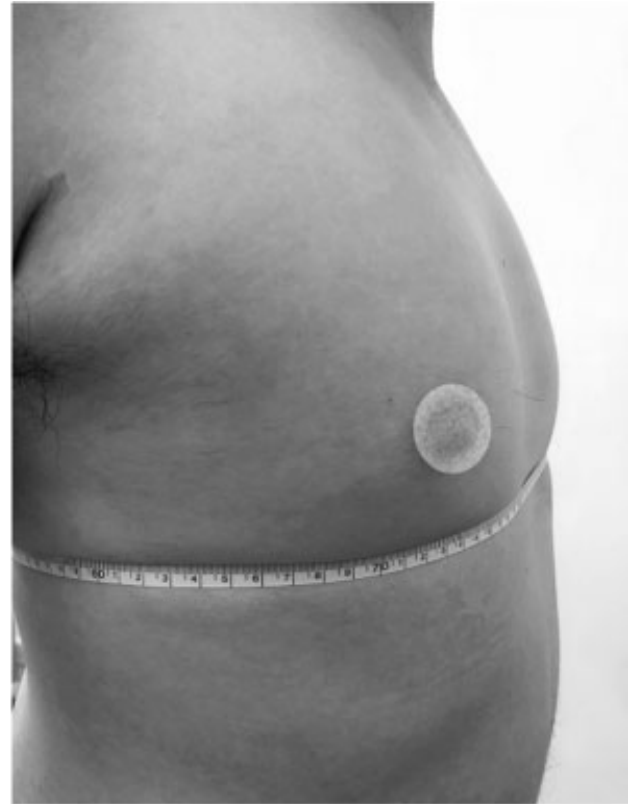

B: on xyphoid level (XL)

Fig. 1 Illustration of measurements on chest circumferences (cirtometry). (A) Level on axillary fold (AL) and (B) level on xyphoid process (XL).

Table 1 Demographic variables and postoperative characteristics of 46 adults with PE corrected by Nuss procedure

\begin{tabular}{|l|l|}
\hline Characteristics & All patients \\
\hline Age, $y$, mean \pm SD & $26.2 \pm 8.6$ \\
\hline Gender (M:F) & $43: 3$ \\
\hline Body height, cm, mean \pm SD & $174.3 \pm 6.6$ \\
\hline Body weight, kg, mean \pm SD & $58.5 \pm 7.7$ \\
\hline Body mass index, kg/m ${ }^{2}$, mean \pm SD & $19.2 \pm 1.9$ \\
\hline Haller index, mean \pm SD & $4.2 \pm 0.9$ \\
\hline Preoperative SVD, $\mathrm{cm}$, mean \pm SD & $7.2 \pm 1.3$ \\
\hline Bar number placed, No. (\%) & $6(13.0)$ \\
\hline Single & $37(80.4)$ \\
\hline Double & $3(6.5)$ \\
\hline Three & $81.8 \pm 19.7$ \\
\hline Operation time, min, mean \pm SD & $14.3 \pm 2.6$ \\
\hline Estimated blood loss, mL, mean \pm SD & $0(0)$ \\
\hline Blood transfusion, No. (\%) & $0(0)$ \\
\hline Mortality, No. (\%) & $6.7 \pm 2.4$ \\
\hline Length of stay, d, mean \pm SD & $9.6 \pm 1.4$ \\
\hline Postoperative SVD ${ }^{\mathrm{b}}, \mathrm{cm}$, mean \pm SD & \\
\hline
\end{tabular}

Abbreviations: PE, pectus excavatum; SD, standard deviation; SVD, sternovertebral distance.

${ }^{a}$ Sternovertebral distance, measured on lateral chest radiograph on deep breath.

${ }^{\mathrm{b}}$ After postoperative follow-up with mean of 16.7 months (12-24 months).

( $n=2)$, flipping of the inserted metal bar $(n=1)$, and incomplete data or loss to follow-up $(n=6)$. Therefore, the data from 46 patients ( 43 men and 3 women), with a mean age of 26.2 years (range, 18-55 years), were included in the analysis. An overview of their demographic features and postoperative results is provided in - Table 1 and - Fig. 2 . The mean SVD after postoperative follow-up with mean of 16.7 months (12-24 months) showed significant improving compared with that before surgery (9.6 \pm 1.4 vs. $7.2 \pm 1.3 \mathrm{~cm}, p<0.01)$.

\section{Circumferential Measurements by Cirtometry}

Chest wall circumference measures at the AL and XL, before and after the Nuss procedure, are summarized in - Fig. 3A, B. The maximal inspiration circumference increased after surgery $(p<0.01$ ) from baseline values prior to surgery, at both the $\mathrm{AL}$ and $\mathrm{XL}$, respectively, as follows: prior to surgery $(84.5 \pm 4.9$ and $80.1 \pm 4.8 \mathrm{~cm})$ and postsurgery at 1 month $(86.6 \pm 5.0$ and $81.6 \pm 4.7 \mathrm{~cm}), 3$ months $(88.5 \pm 5.1$ and $83.7 \pm 5.1 \mathrm{~cm})$, and 6 months $(88.9 \pm 4.7$ and $84.3 \pm 4.8 \mathrm{~cm}$ ). At both the AL and XL, measures at 3 and 6 months after surgery were not significantly different $(p>0.01)$. A similar pattern of increase in the chest wall circumference was identified for maximal expiration at both the AL and $\mathrm{XL}(p<0.01)$, respectively, as follows: prior to surgery $(79.9 \pm 5.2$ and $74.2 \pm 5.0 \mathrm{~cm})$ and postsurgery at 1 month $(81.9 \pm 5.6$ and $76.7 \pm 5.5 \mathrm{~cm}), 3$ months $(83.3 \pm 5.0$ and $78.2 \pm 5.1 \mathrm{~cm})$, and 6 months $(83.5 \pm 5.0$ and $78.3 \pm 5.1 \mathrm{~cm})$. At both the AL and XL, measures at 3 and 6 months after surgery were not significantly different $(p>0.01)$.

\section{Exercise/Fitness Capacity}

The BMI was assessed at each follow-up visit after surgery, calculated after removing the weight of the inserted bar(s) $(0.4 \mathrm{~kg} / \mathrm{bar})$, with no difference between the pre- and postoperative BMI values $(p>0.01)$. 


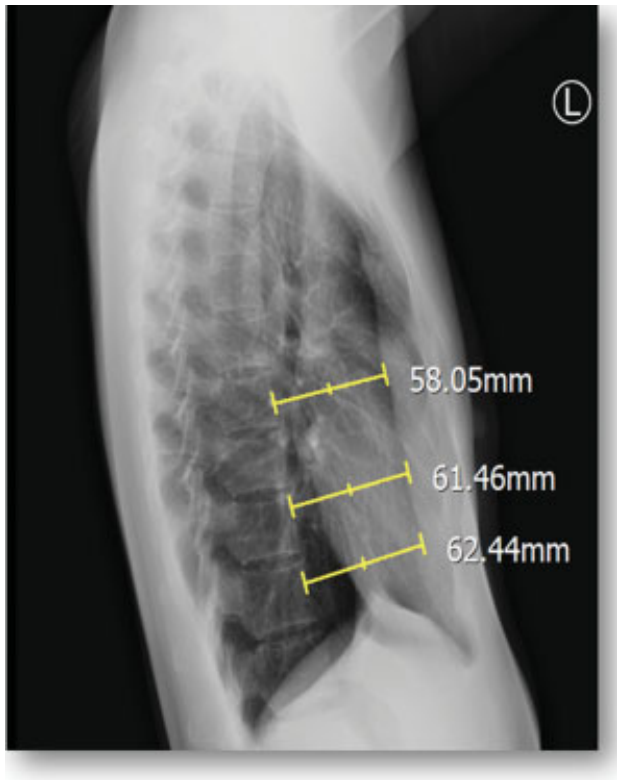

A: Before operation

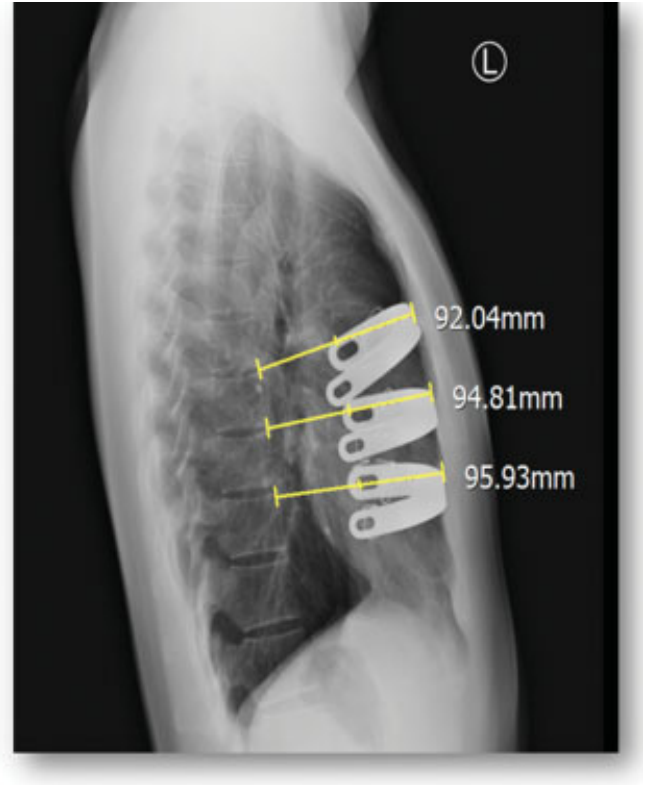

B: 12 months after operation

Fig. 2 Lateral chest plain films of a 21-year-old man before and 12 months after Nuss procedure. Three bars were placed into the thoracic cage. Sternovertebral distance was measured as demonstrated using yellow lines. The correction of chest wall deformity was evident.

The results of the 6MWT are shown in - Fig. 4. Compared with that before surgery $(545.8 \pm 65.0 \mathrm{~m})$, the maximum walking distance improved at 3 months $(627.8 \pm 61.5 \mathrm{~m}$, $p<0.001)$ and 6 months after surgery $(658.5 \pm 52.8 \mathrm{~m}$, $p<0.001$ ), but was not significantly different at 1 month after surgery ( $535.7 \pm 94.9 \mathrm{~m}, p=0.396$ ). Furthermore, the maximum walking distance was significantly different between 1 and 3 months after surgery $(p<0.001)$, and between 3 and 6 months after surgery $(p<0.001)$.

\section{Correlation between the Chest Wall Circumference and the 6MWT}

Significant correlations between the improvement in chest wall circumference on maximal inspiration and the 6MWT result were identified at the AL and XL (Pearson's correlation coefficient, 0.8424 and 0.7951 , respectively). These positive correlations support an association between increased exercise capacity and an increased expansion of the anterior chest wall after Nuss correction in adults with PE.

\section{Discussion}

The present study demonstrated that improved dynamics of the thoracic cage were achieved after Nuss repair for PE in adults. Generally, patients with PE undergo surgical correction to improve cosmetic, psychosocial, and/or physiological concerns. $^{2-4}$ The Nuss repair is a minimally invasive technique for PE correction. ${ }^{5}$ After its introduction in 1998, Nuss correction became widely accepted and popular, as it required minimal resection while providing good cosmetic and functional results. ${ }^{2,7-9}$ Originally, the Nuss procedure was developed primarily for the correction of PE in prepubertal children, with an optimal age for correction of 12 to
16 years. ${ }^{5,17}$ However, recent studies have also demonstrated satisfactory outcomes of this procedure for correction of PE in adults, regardless of age. ${ }^{4,16-18}$

Morphological changes in the thoracic cage, after the Nuss procedure, have been previously evaluated using chest imaging (CT or radiography $)^{18-21}$ and optoelectronic plethysmography. ${ }^{22,23}$ These studies demonstrated an increase in the volume of the thoracic cage or static lung volume after surgical correction. In the present study, we also evaluated radiological changes of chest wall after surgical repair using SVD measured by lateral chest radiographs. The results showed a significant increase after Nuss procedure.

However, the effect of the correction on the dynamics of the thoracic cage during inspiration and expiration had not been well characterized to date. In 1972, Moll and Wright demonstrated the reliability of measuring chest expansion using a measuring tape $(\mathrm{cm})$ in an objective clinical study. ${ }^{24}$ Since its introduction, this technique has been described as cirtometry or thoracoabdominal measurement by some academics, and has been used to quantify the mobility of the chest wall. ${ }^{10,11}$ The information of key studies concerning cirtometry is summarized in - Table 2. Cirtometry plays an important role in the assessment of patients with a variety of disease conditions, such as ankylosing spondylitis, asthma, and chronic obstructive pulmonary disease, as well as to investigate the effects of physical treatments designed to improve respiratory function. ${ }^{25-28}$ The intra- and interrater reliabilities and reproducibility of thoracoabdominal measurements in patients with various diseases have been reported to be fair to good, with greater variability for interrater measurements. ${ }^{10}$ Based on this evidence, all cirtometry measurements in the present study were obtained by one experienced rater, with the rater blinded to clinical and 6MWT data. 

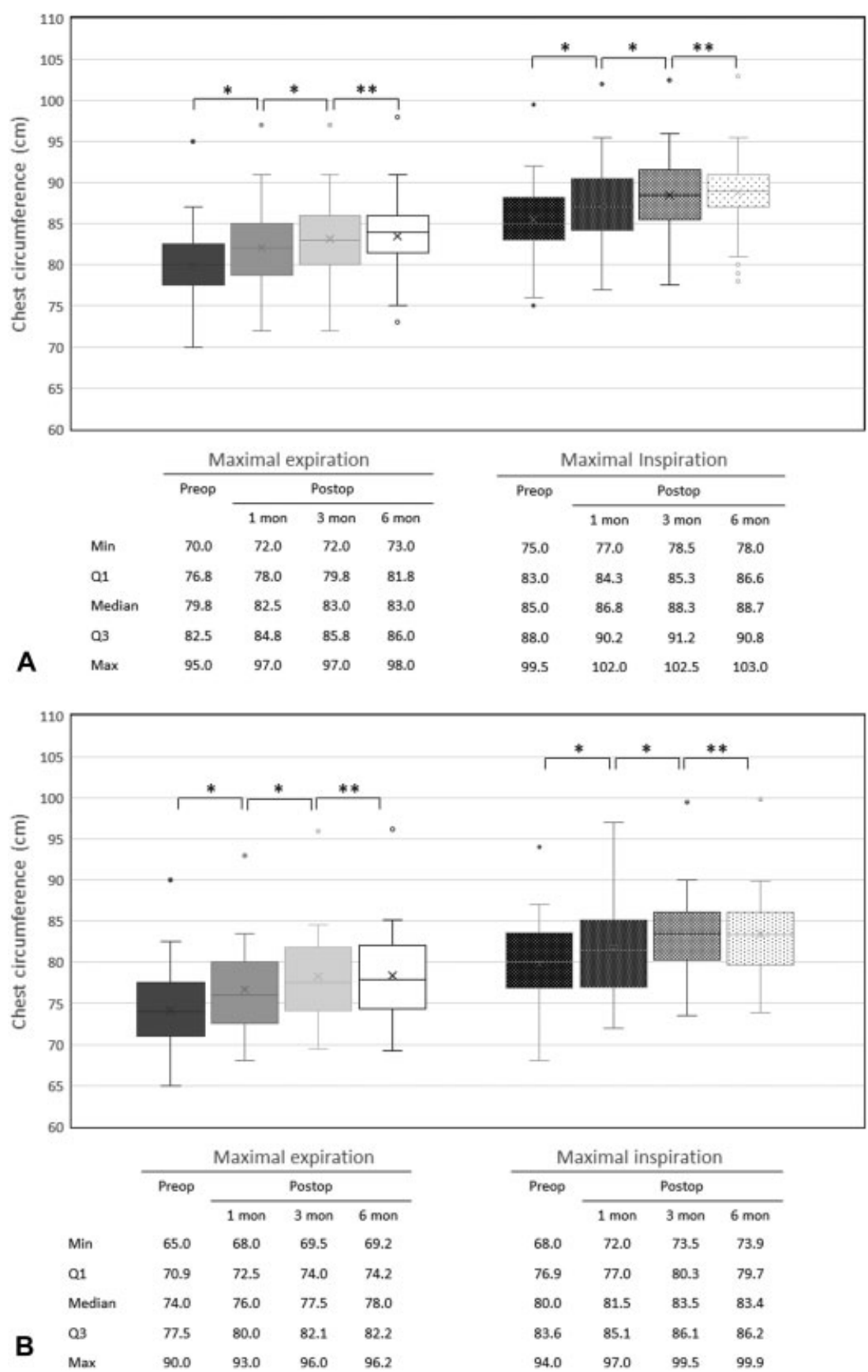

Fig. 3 Changes in chest wall circumference at the (A) axillary and (B) xyphoid levels at four time points: preoperatively and at 1, 3, and 6 months after surgery on maximal inspiration (right) and maximal expiration (left). The minimum, first quartile (Q1), median, third quartile (Q3), and maximum values are presented in box-and-whisker plots; actual measurements are marked on the plots and annotated under the figures. ${ }^{*} p<0.01,{ }^{* *} p \geq 0.01$. mon, month; preop, before surgery; postop, after surgery.

Numerous studies have investigated changes in lung volume and pulmonary function after the Nuss procedure, with controversial results. ${ }^{8,22,29}$ However, in our clinical experience, most patients cannot complete standard pulmonary spirometry and cardiopulmonary exercise testing (CPET) after the Nuss procedure, due to pain that can persist up to 3 months after surgery. Thus, the use of pulmonary spirometry and CPET data might not be suitable for repeated follow-up, especially in the early postoperative period. For these reasons, the 6MWT, which was used in the present study, would provide a more suitable proxy measure of the change in exercise capacity, before and after the surgery. The maximal walking distance in 6 minutes has been previously used as a reliable measure of the effect of new therapies or interventions on exercise capacity. ${ }^{12,13}$

In the present study, we identified a significant improvement in the excursion of the thoracic cage by 1 month after Nuss correction for PE in adults, with improvement stabilizing at 3 months after surgery. The increase in thoracic 


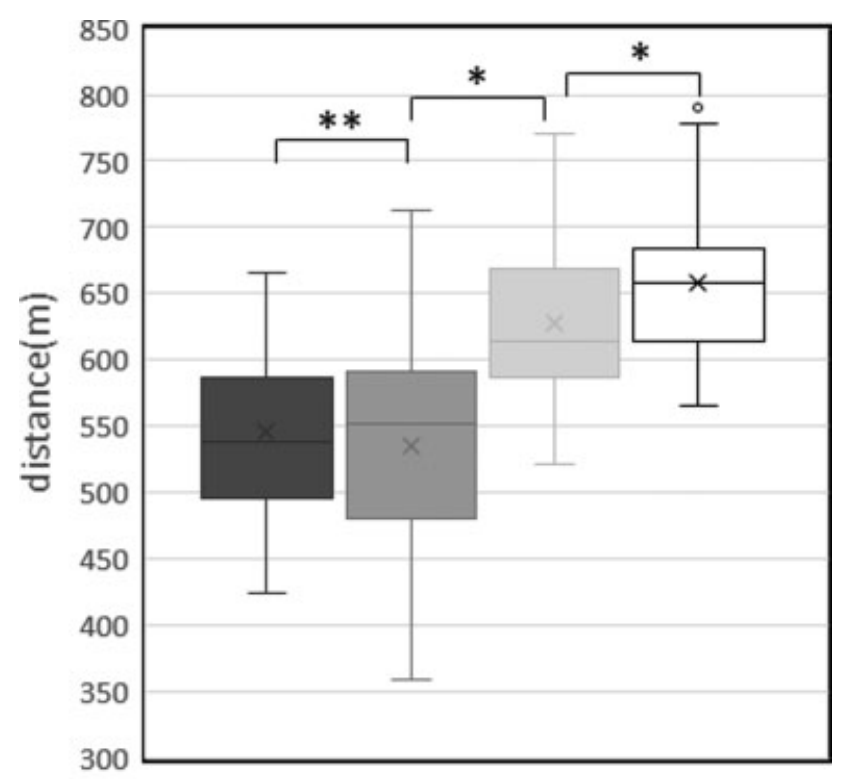

6MWT

\begin{tabular}{lllll} 
& Preop & \multicolumn{3}{c}{ Postop } \\
\cline { 3 - 5 } & & $1 \mathrm{mon}$ & $3 \mathrm{mon}$ & $6 \mathrm{mon}$ \\
Min & 425.0 & 243.6 & 521.0 & 565.0 \\
Q1 & 496.3 & 480.0 & 586.3 & 614.8 \\
Median & 539.0 & 551.5 & 613.5 & 658.5 \\
Q3 & 586.8 & 591.1 & 669.3 & 684.4 \\
Max & 665.0 & 712.5 & 771.0 & 790.0
\end{tabular}

Fig. 4 A box-and-whisker plot of the walking distance, measured using the 6-minute walk test (6MWT), before surgery and at 1,3 , and 6 months after surgery. The minimum, first quartile (Q1), median, third quartile (Q3), and maximum values are marked on the plots and annotated under the figures. ${ }^{*} p<0.01,{ }^{* *} p \geq 0.01$. mon, month; preop, before surgery; postop, after surgery. volume at 3 months postsurgery was associated with an increase in the maximal walking distance on the 6MWT. The lack of improvement in the maximal walking distance at 1 month after surgery likely results from early postoperative pain. All observed increases in postoperative chest wall excursion (at both the AL and XL and at the end points of both inspiration and expiration) were correlated with the increase in the maximum walking distance (all Pearson's correlation coefficients $>0.7$ ). Therefore, the increase in chest wall circumference reflects the increase in functional exercise capacity, with both cirtometry and the 6MWT providing simple and reliable ways for surgeons to monitor the clinical and functional outcomes of patients undergoing a Nuss procedure.

The limitations of the present study should be acknowledged. Foremost, the number of patients was relatively small. Thus, further studies with larger numbers of patients and subgroup analyses are needed to confirm our findings. Furthermore, we only selected adults for evaluation because possible skeletal growth may occur in younger patients. Additionally, further studies on the changes in chest wall mobility and physiological benefits of the Nuss procedure in patients with PE are needed after the removal of the stainless steel bar(s).

In conclusion, cirtometry is a simple, readily available, and replicable method to evaluate changes in chest wall dynamics after Nuss correction of PE in adults. The chest wall circumference at different levels significantly improved after surgery, with the improvement in chest excursion stabilizing at 3 months after surgery. This postcorrection improvement in chest wall mobility was highly correlated with exercise capacity. Future studies should evaluate the maintenance of benefits after the removal of the supporting $\operatorname{bar}(\mathrm{s})$.

Table 2 Summary of key studies concerning cirtometry on clinical disorders

\begin{tabular}{|c|c|c|}
\hline Study & Objective & Results and conclusions \\
\hline $\begin{array}{l}\text { Debouche et al } \\
(2016)^{10}\end{array}$ & $\begin{array}{l}\text { 1. Assessing the reliability and reproducibility of chest } \\
\text { wall expansion measurement in young healthy adults } \\
\text { 2. Examine the correlation between upper and lower } \\
\text { chest expansion measurements and lung function }\end{array}$ & $\begin{array}{l}\text { 1. Good intra- and interrater reliabilities and repro- } \\
\text { ducibility were found in either upper or lower chest } \\
\text { wall expansion measurement } \\
\text { 2. Both upper and lower chest wall measurements } \\
\text { were correlated with pulmonary function, but } \\
\text { upper measurements may be more useful }\end{array}$ \\
\hline $\begin{array}{l}\text { Caldeira et al } \\
(2007)^{11}\end{array}$ & $\begin{array}{l}\text { 1. To examine the intra- and interrater reliabilities } \\
\text { 2. Correlation between cirtometry and pulmonary } \\
\text { volumes measured by respiratory inductive } \\
\text { plethysmography }\end{array}$ & $\begin{array}{l}\text { 1. Intrarater reliability was satisfactory, but significant } \\
\text { differences were noted in all sets of interrater } \\
\text { measurements } \\
\text { 2. Cirtometry does not accurately reflects lung } \\
\text { volumes }\end{array}$ \\
\hline $\begin{array}{l}\text { Moll and } \\
\text { Wright } \\
(1972)^{24}\end{array}$ & $\begin{array}{l}\text { 1. To determine the normal range of cheat wall movement } \\
\text { 2. To evaluate the effect of different diseases on chest } \\
\text { expansion, including ankylosing spondylitis, chronic chest } \\
\text { disease, and obesity }\end{array}$ & $\begin{array}{l}\text { 1. A wide scatter of normal values was observed at all } \\
\text { decades and showed wide variation with age and sex } \\
\text { 2. Circumferential measurement alone would be ade- } \\
\text { quate for usual purposes }\end{array}$ \\
\hline $\begin{array}{l}\text { Grubisić et al } \\
(2014)^{25}\end{array}$ & $\begin{array}{l}\text { To determine the relationship between the bone mineral } \\
\text { density, spinal mobility, and chest expansion index in } \\
\text { patients with ankylosing spondylitis }\end{array}$ & $\begin{array}{l}\text { Thoracic and lumbar spine mobility and chest } \\
\text { expansion index decreased in patients with lower } \\
\text { bone mineral density in lumbar and hip region }\end{array}$ \\
\hline
\end{tabular}


Table 2 (Continued)

\begin{tabular}{|l|l|l|}
\hline Study & Objective & Results and conclusions \\
\hline $\begin{array}{l}\text { Johansson et al } \\
(2012)^{26}\end{array}$ & $\begin{array}{l}\text { Comparing chest mobility, respiratory movement, and } \\
\text { pain sensitivity in SHR patients with patients with } \\
\text { asthma, COPD, and alleged healthy control subjects }\end{array}$ & $\begin{array}{l}\text { SHR patients demonstrated signs of dysfunctional } \\
\text { breathing and seemed to be most similar to patients } \\
\text { with COPD group except for lung function }\end{array}$ \\
\hline $\begin{array}{l}\text { Malaguti et al } \\
(2009)^{27}\end{array}$ & $\begin{array}{l}\text { 1. Evaluating the reliability and accuracy of cirtometry } \\
\text { 2. Investigating the relationship between chest wall } \\
\text { mobility and inspiratory capacity in patients with } \\
\text { COPD }\end{array}$ & $\begin{array}{l}\text { 1. High reliability of intra- and interobserver mea- } \\
\text { surements } \\
\text { 2. An association between inspiratory capacity and } \\
\text { chest measurements at the abdominal level was } \\
\text { found, but the results showed no correlation } \\
\text { between chest wall mobility and pulmonary } \\
\text { function }\end{array}$ \\
\hline
\end{tabular}

Abbreviations: COPD, chronic obstructive pulmonary disease; SHR, sensory hyperreactivity.

Financial Support

This work was not supported by any funding agency.

Conflict of Interest

None declared.

\section{References}

1 Brochhausen C, Turial S, Müller FK, et al. Pectus excavatum: history, hypotheses and treatment options. Interact Cardiovasc Thorac Surg 2012;14(06):801-806

2 Nuss D, Kelly RE Jr. Indications and technique of Nuss procedure for pectus excavatum. Thorac Surg Clin 2010;20(04):583-597

3 Kragten HA, Siebenga J, Höppener PF, Verburg R, Visker N. Symptomatic pectus excavatum in seniors (SPES): a cardiovascular problem? A prospective cardiological study of 42 senior patients with a symptomatic pectus excavatum. Neth Heart J 2011;19(02):73-78

4 Jaroszewski DE, Ewais MM, Chao CJ, et al. Success of minimally invasive pectus excavatum procedures (modified Nuss) in adult patients ( $\geq 30$ years). Ann Thorac Surg 2016;102(03):993-1003

5 Nuss D, Kelly RE Jr, Croitoru DP, Katz ME. A 10-year review of a minimally invasive technique for the correction of pectus excavatum. J Pediatr Surg 1998;33(04):545-552

6 Maagaard M, Tang M, Ringgaard S, et al. Normalized cardiopulmonary exercise function in patients with pectus excavatum three years after operation. Ann Thorac Surg 2013;96(01):272-278

7 Tang M, Nielsen HH, Lesbo M, et al. Improved cardiopulmonary exercise function after modified Nuss operation for pectus excavatum. Eur J Cardiothorac Surg 2012;41(05):1063-1067

8 Malek MH, Berger DE, Marelich WD, Coburn JW, Beck TW, Housh TJ. Pulmonary function following surgical repair of pectus excavatum: a meta-analysis. Eur J Cardiothorac Surg 2006;30(04):637-643

9 Malek MH, Berger DE, Housh TJ, Marelich WD, Coburn JW, Beck TW. Cardiovascular function following surgical repair of pectus excavatum: a metaanalysis. Chest 2006;130(02):506-516

10 Debouche S, Pitance L, Robert A, Liistro G, Reychler G. Reliability and reproducibility of chest wall expansion measurement in young healthy adults. J Manipulative Physiol Ther 2016;39(06):443-449

11 Caldeira VdaS, Starling CC, Britto RR, Martins JA, Sampaio RF, Parreira VF. Reliability and accuracy of cirtometry in healthy adults. J Bras Pneumol 2007;33(05):519-526

12 Rasekaba T, Lee AL, Naughton MT, Williams TJ, Holland AE. The six-minute walk test: a useful metric for the cardiopulmonary patient. Intern Med J 2009;39(08):495-501

13 ATS Committee on Proficiency Standards for Clinical Pulmonary Function Laboratories. ATS statement: guidelines for the six-minute walk test. Am J Respir Crit Care Med 2002;166(01):111-117

14 Haller JA Jr, Kramer SS, Lietman SA. Use of CT scans in selection of patients for pectus excavatum surgery: a preliminary report. J Pediatr Surg 1987;22(10):904-906
15 Wu TH, Huang TW, Hsu HH, et al. Usefulness of chest images for the assessment of pectus excavatum before and after a Nuss repair in adults. Eur J Cardiothorac Surg 2013;43(02):283-287

16 Cheng YL, Lee SC, Huang TW, Wu CT. Efficacy and safety of modified bilateral thoracoscopy-assisted Nuss procedure in adult patients with pectus excavatum. Eur J Cardiothorac Surg 2008;34 (05):1057-1061

17 Kelly RE, Goretsky MJ, Obermeyer R, et al. Twenty-one years of experience with minimally invasive repair of pectus excavatum by the Nuss procedure in 1215 patients. Ann Surg 2010;252(06): 1072-1081

18 Sacco Casamassima MG, Gause C, Goldstein SD, et al. Patient satisfaction after minimally invasive repair of pectus excavatum in adults: long-term results of Nuss procedure in adults. Ann Thorac Surg 2016;101(04):1338-1345

19 Chang PY, Zeng Q Wong KS, et al. A cross-sectional study of chest wall development in patients with pectus excavatum. Thorac Cardiovasc Surg 2015;63(05):433-436

20 Kilda A, Lukosevicius S, Barauskas V, Jankauskaite Z, Basevicius A. Radiological changes after Nuss operation for pectus excavatum. Medicina (Kaunas) 2009;45(09):699-705

21 Nakagawa Y, Uemura S, Nakaoka T, Yano T, Tanaka N. Evaluation of the Nuss procedure using pre- and postoperative computed tomographic index. J Pediatr Surg 2008;43(03):518-521

22 Acosta J, Bradley A, Raja V, et al. Exercise improvement after pectus excavatum repair is not related to chest wall function. Eur J Cardiothorac Surg 2014;45(03):544-548

23 Redlinger RE Jr, Wootton A, Kelly RE, et al. Optoelectronic plethysmography demonstrates abrogation of regional chest wall motion dysfunction in patients with pectus excavatum after Nuss repair. J Pediatr Surg 2012;47(01):160-164

24 Moll JM, Wright V. An objective clinical study of chest expansion. Ann Rheum Dis 1972;31(01):1-8

25 Grubisić F, Grazio S, Balenović A, Nemcić T, Kusić Z. Osteoporosis, spinal mobility and chest expansion index in patients with ankylosing spondylitis. Coll Antropol 2014;38(01):63-68

26 Johansson EL, Ternesten-Hasséus E, Olsén MF, Millqvist E. Respiratory movement and pain thresholds in airway environmental sensitivity, asthma and COPD. Respir Med 2012;106(07): 1006-1013

27 Malaguti C, Rondelli RR, de Souza LM, Domingues M, Dal Corso S. Reliability of chest wall mobility and its correlation with pulmonary function in patients with chronic obstructive pulmonary disease. Respir Care 2009;54(12):1703-1711

28 Lanza FdeC, de Camargo AA, Archija LR, Selman JP, Malaguti C, Dal Corso $\mathrm{S}$. Chest wall mobility is related to respiratory muscle strength and lung volumes in healthy subjects. Respir Care 2013;58(12):2107-2112

29 Wang Q, Fan S, Wu C, Jin X, Pan Z, Hong D. Changes in resting pulmonary function testing over time after the Nuss procedure: a systematic review and meta-analysis. J Pediatr Surg 2018;53(11): 2299-2306 